\section{Inheritance of Esterase, Diaphorase, and Glucose-6-phosphate Isomerase in Lisianthus}

\author{
David B. Rubino ${ }^{1}$ \\ Florist and Nursery Crops Laboratory, Agricultural Research Service, U.S. \\ Department of Agriculture, Beltsville, MD 20705-2350 \\ Additional index words. Eustoma grandiflorum, prairie gentian, isozymesr
}

\begin{abstract}
Segregating lisianthus [Eustoma grandiflorum (Griseb.) Shinn.] progeny were evaluated to determine the inheritance of esterase (EST), diaphorase (DIA), and glucose-6-phosphate isomerase (GPI) isozymes. Phenotypic data supported the hypotheses that EST is monomeric and controlled by one locus (Est1) with at least three alleles, DIA is tetrameric and controlled by one locus (Dia2) with at least two alleles, and GPI is controlled by one locus (Gpil) with at least two alleles. The structure of the GPI isozyme could not be inferred from banding patterns. Joint segregation analyses indicated that the three loci segregate independently. These three isozymes are the first simply inherited, unlinked biochemical markers identified in lisianthus. These marker loci will be useful for genetic studies, breeding, and germplasm characterization.
\end{abstract}

Lisianthus is an important cut flower, bedding plant, and potted plant (Halevy and Kofranek, 1984; Roh and Lawson, 1984; Rubino, 1992). Although breeding programs continue to produce improved cultivars, basal branch count is the only characteristic that has been investigated genetically (Griesbach and Semeniuk, 1987). The chromosome number for lisianthus is $2 \mathrm{n}=2 \mathrm{x}=36$ (Griesbach and Bhat, 1990).

Genetically defined, simply inherited markers are lacking in lisianthus. Isozyme loci have been used in ornamental species for germplasm characterization (Kobayashi et al., 1987; Messeguer and Ares, 1985; Sumanasinghe, 1986; Wendel and Parks, 1982) since they often can be evaluated in young seedlings; exhibit Mendelism inheritance, codominance, and complete penetrance; and lack pleiotropic and epistatic interactions (Weeden and Wendel, 1989). Screening cultivated lisianthus germplasm has revealed variation in banding patterns for three isozyme systems: esterase (EST; E.C. 3.1..1.-), diaphorase (DIA; E.C. 1.6.99.-), and glucose-6-phosphate isomerase (GPI; E.C. 5.3. 1.9) (Rubino, 1991). The investigation reported here was conducted to determine the inheritance and linkage rela-

Received for publication 11 Sept. 1992. Accepted for publication 28 Dec. 1992. I gratefully acknowledge the technical support of Suzy Flowers and Agnes van der Hulst and the financial assistance of the Fred C. Gloeckner Foundation. Germplasm was generously provided by Sakata Seed America, American Takii, and Mikado Seed Co. Mention of a trade name or proprietary product does not constitute a guarantee or warranty by the U.S. Dept. of Agriculture and does not imply approval to the exclusion of other products that may also be suitable. The cost of publishing this paper was defrayed in part by the payment of page charges. Under postal regulations, this paper therefore must be hereby marked advertisement solely to indicate this fact. 'Research Geneticist. tionships of loci controlling these three isozyme systems.

Five cultivars were used as parents in the study (Table 1). Seeds were germinated under intermittent mist, transplanted to $70-\mathrm{ml}$ cell packs, and grown in a $25 \mathrm{C}$ glasshouse in Est 1-2) progeny. Origin is at the top of the photograph.
Beltsville, Md., from Dec. 1991 through Mar. 1992.

About $0.015 \mathrm{~g}$ of tissue from fully expanded leaves of nonreproductive plants was crushed in extraction buffer (Stuber et al., 1988 ) in 0.5 -ml polypropylene centrifuge tubes on top of ice. Extracts were frozen at $-70 \mathrm{C}$ until electrophoresis was conducted. Plants sampled before internode elongation produced weak activity for EST. Consequently, samples for EST analysis were obtained from plants that had initiated internode elongation (97 to 104 days after planting). For DIA and GPI, plants were sampled before internode elongation (70 to 90 days after planting), although plants sampled at later developmental stages produced banding patterns that were qualitatively identical to patterns from plants sampled at earlier stages.

Samples were absorbed with no. 903 filter paper wicks (Schleicher and Schuell, Keene, N.H.), blotted on tissue paper, and loaded into 345-ml 13\% horizontal starch gels. Gel buffers were lithium borate-tris.citrate, $\mathrm{pH} 8.3$ (C gel), for EST, tris·citrate, $\mathrm{pH} 7.0$ (F gel), for DIA; and histidine-citrate, pH 5.7 (B gel), for GPI (Stuber et al., 1988).

Electrophoresis was conducted at $4 \mathrm{C}$, and gels were covered with cold water and ice packs. $C$ gels were run at $60-\mathrm{mA}$ constant for $4.25 \mathrm{~h}, \mathrm{~F}$ gels at $90 \mathrm{~mA}$ for $5 \mathrm{~h}$, and B gels at $85 \mathrm{~mA}$ for $5 \mathrm{~h}$. Wicks were removed from gels

Table 1. Lisianthus cultivars used for the genetic analysis of esterase, diaphorase, and glucose-6-phosphate isomerase and their proposed respective genotypes for Est1, Dia2, and Gpi1 isozyme loci.

\begin{tabular}{lcccc}
\hline & & & \multicolumn{2}{c}{ Isozyme locus } \\
\cline { 3 - 5 } Cultivar & \multicolumn{1}{c}{ Source } & Est 1 & Dia2 & Gpil \\
\cline { 3 - 5 } & & & $1 / 2$ & $1 / 1$ \\
Mermaid Blue & Sakata Seed America & $2 / 2$ & $2 / 2$ \\
Reidi Deep Blue & Sakata Seed America & $2 / 3$ & $1 / 2$ & $1 / 2$ \\
Royal Light Purple & American Takii & $2 / 2$ & $1 / 1$ & $1 / 2$ \\
Pink & American Takii & $1 / 2$ & $1 / 1$ & $2 / 2$ \\
\hline
\end{tabular}

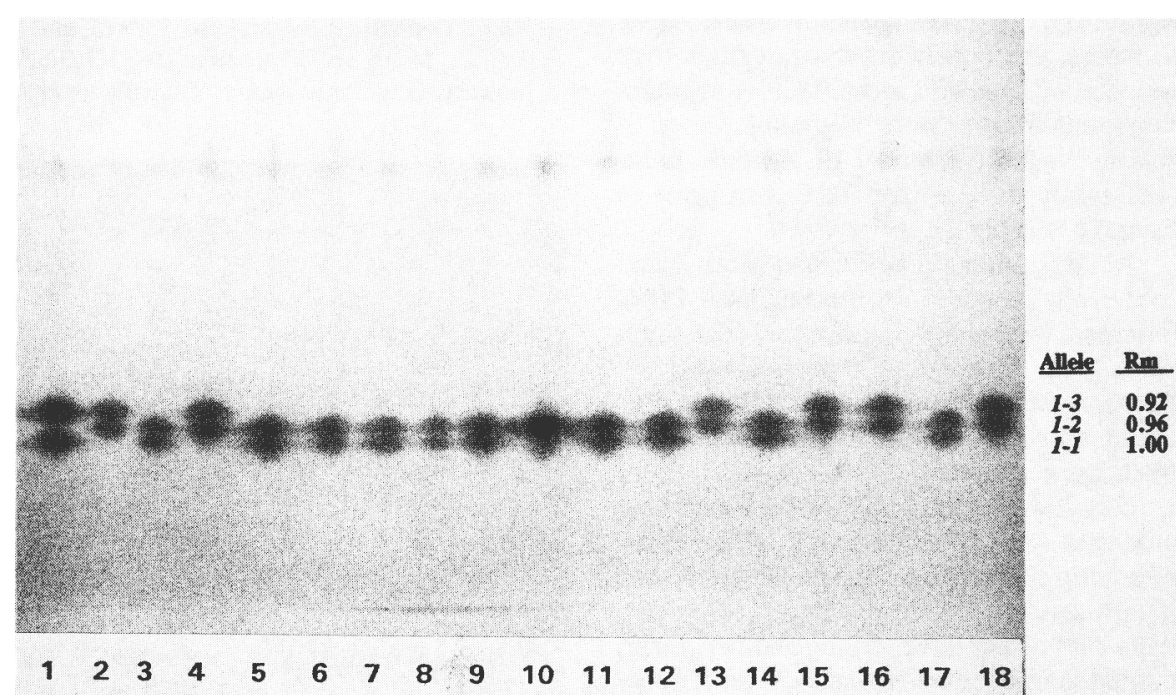

Fig. 1. Esterase phenotypes observed in progeny resulting from the cross of the lisianthus cultivars Pink $x$ Royal Light Purple. Control lane 1 is a sample from the heterozygous (Est1-1/Est1-3) 'Pink' parent; lane 10 is from the homozygous (Est1 -2/Est1 -2) 'Royal Light Purple' parent; and lanes 2,4, 13,15, 16, and 18 are from heterozygous (Est1-2/Est1-3) progeny. All other lanes are from heterozygous (Est1-1/ 


\section{Breeding and Genetics}

Table 2. Genotypic ratios and $X^{2}$ values for goodness-of-fit for esterase (Estl), diaphorase (Dia2), and glucose-6-phosphate isomerase (Gpil) loci in lisianthus progeny.

\begin{tabular}{|c|c|c|c|c|c|c|c|c|}
\hline \multirow[b]{2}{*}{ Locus, cross } & \multicolumn{5}{|c|}{ Segregation classes } & \multirow{2}{*}{$\begin{array}{l}\text { Test } \\
\text { ratio }\end{array}$} & \multirow[b]{2}{*}{$X^{2}$} & \multirow[b]{2}{*}{$P$} \\
\hline & $1 / 1$ & $1 / 2$ & $2 / 2$ & $2 / 3$ & $3 / 3$ & & & \\
\hline \multicolumn{9}{|l|}{ Est1 } \\
\hline Pink $\times$ Royal Light Purple & --- & 34 & --- & 37 & --- & $1: 1$ & 0.13 & 0.72 \\
\hline Royal Light Purple $\times$ Pink & --- & 43 & -- & 27 & --- & $1: 1$ & 3.66 & 0.06 \\
\hline Royal Violet (self) & 11 & 38 & 17 & --- & --- & $1: 2: 1$ & 2.61 & 0.27 \\
\hline Heidi Deep Blue (self) & --- & --- & 22 & 34 & 15 & $1: 2: 1$ & 1.51 & 0.47 \\
\hline Mermaid Blue (self) ${ }^{2}$ & --- & --- & 32 & --- & --- & --- & --- & --- \\
\hline \multicolumn{9}{|l|}{ Dia2 } \\
\hline Pink $\times$ Royal Light Purple & 38 & 33 & --- & --- & --- & $1: 1$ & 0.35 & 0.55 \\
\hline Royal Light Purple $x$ Pink & 30 & 42 & --- & --- & --- & $1: 1$ & 2.00 & 0.16 \\
\hline Heidi Deep Blue (self) & 13 & 37 & 22 & --- & --- & $1: 2: 1$ & 2.31 & 0.32 \\
\hline Mermaid Blue (self) & 32 & -- & --- & --- & --- & --- & --- & --- \\
\hline \multicolumn{9}{|l|}{ Gpil } \\
\hline Pink $\times$ Royal Light Purple & --- & 28 & 43 & --- & --- & $1: 1$ & 3.17 & 0.08 \\
\hline Royal Light Purple $\times$ Pink & $\ldots$ & 44 & 27 & --- & --- & $1: 1$ & 4.07 & 0.04 \\
\hline Royal Violet (self) & 18 & 34 & 20 & $\ldots$ & --- & $1: 2: 1$ & 0.33 & 0.85 \\
\hline Mermaid Blue (self) ${ }^{2}$ & 32 & -- & -- & --- & --- & --- & --- & --- \\
\hline
\end{tabular}

${ }^{2}$ Nonsegregating control.

after 30 min to improve resolution. After electrophoresis, gels were sliced horizontally. The bottom slice $(\approx 2 \mathrm{~mm}$ thick) was stained using the methods of Stuber et al. (1988), except $\alpha$ - naphthylacetate was not added for EST.

Relative migration $(\mathrm{Rm})$ distances were calculated as the ratios of the individual isozyme bands to the fastest migrating band in the control lanes. The nomenclature of Mowrey et. al. (1990) was used with the most-anodal locus designated as 1 and the most-anodal allele for a locus designated as 1 ; slower migrating alleles were assigned progressively higher numbers. Goodness-of-fit of allelic segregation ratios to expected ratios and possible linkages among loci were tested by chi-square analysis using the computer program LINKAGE-1 (Suiter et al., 1983).

EST. Four anodal regions of activity were revealed for EST. The fastest migrating region produced sharply defined bands, while the three slower migrating regions were lightly stained and not well resolved (Fig. 1). Plant esterases have been reported to be controlled by two to 10 loci (Weeden and Wendel, 1989); therefore, the poorly resolved regions may reflect additional EST loci. Observed segregation ratios for the fastest migrating region of activity support a model of a single locus (Est 1) with three alleles for this isozyme in lisianthus (Table 2).

Allelic designations of Est1 -1, Est1 -2, and Est 1 -3 are proposed for the fast (Rm 1.00), intermediate ( $\mathrm{Rm}$ 0.96), and slow ( $\mathrm{Rm} 0.92)$ bands in the Est1 region, respectively (Fig. 1). Plants heterozygous at the Est1 locus produced a two-band pattern that reflected the monomeric structure of this isozyme.

$D I A$. Two anodal regions of activity were produced with poor resolution of the faster migrating region (Fig. 2). The slower region (Dia2) produced three distinct banding patterns with two or three trailing and two faster, lightly staining shadow bands. The shadow bands were more apparent in homozygotes and could be the result of post-translational modification or confirmational changes during sample preparation or electrophoresis (Wendel and Weeden, 1989).

A model of a single locus with two alleles

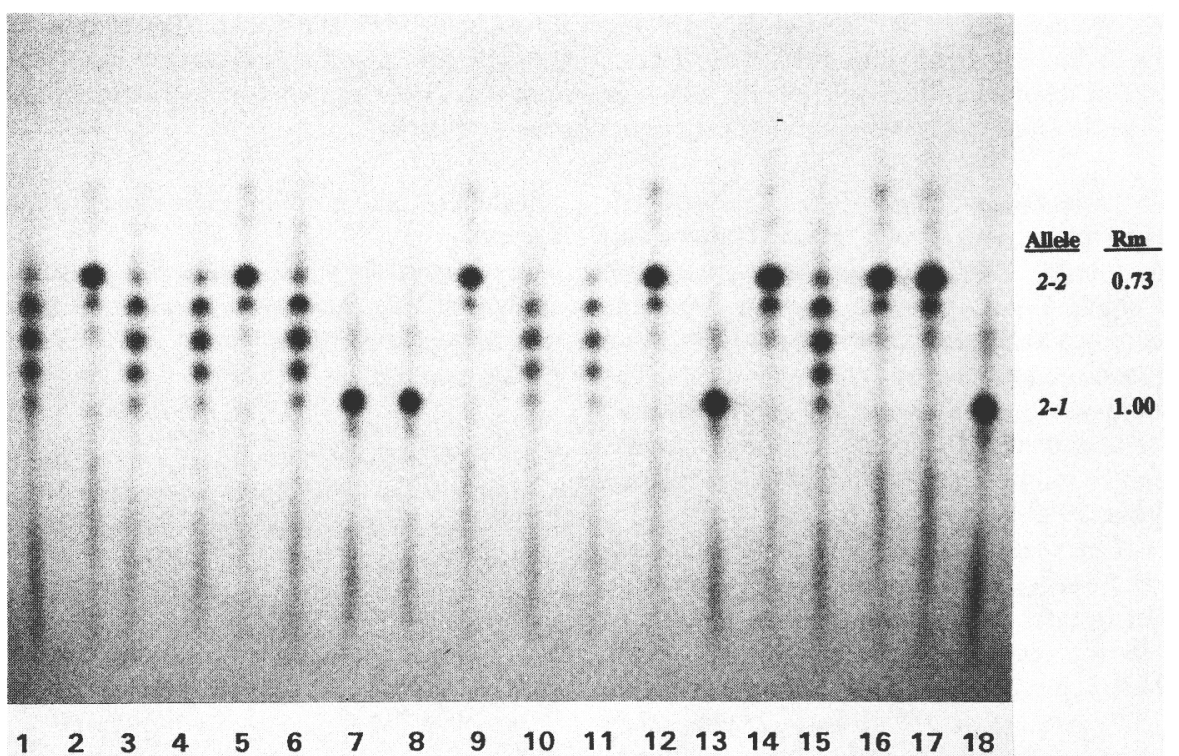

Fig. 2. Diaphorase phenotypes observed in progeny resulting from the self-pollination of the lisianthus cultivar Heidi Deep Blue. Control lanes 1 and 10 are samples from the heterozygous (Dia2-1/Dia2-2) 'Heidi Deep Blue' parent; lanes 7,8, 13, and 18 are from (Dia2-1/Dia2-1) homozygotes; and lanes 2, $5,9,12,14,16$, and 17 are from (Dia2-2/Dia2-2) homozygotes. All other lanes are from heterozygous progeny. Origin is at the top of the photograph.

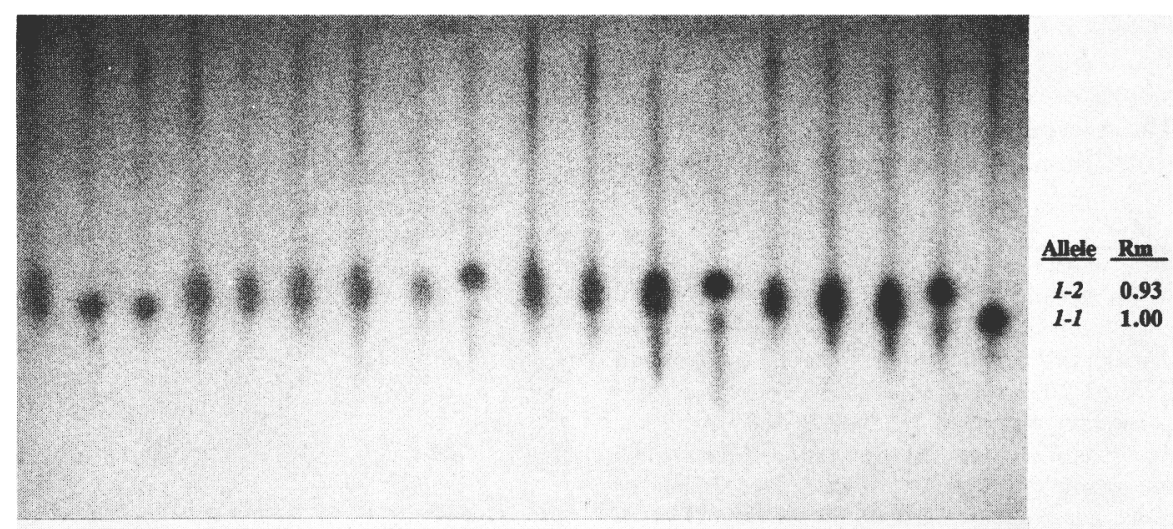

$\begin{array}{llllllllllllllllll}1 & 2 & 3 & 4 & 5 & 6 & 7 & 8 & 9 & 10 & 11 & 12 & 13 & 14 & 15 & 16 & 17 & 18\end{array}$

Fig. 3. Glucose-6-phosphate isomerase phenotypes observed in progeny resulting from the self-pollination of the lisianthus cultivar Royal Violet. Control lanes 1 and 10 are samples from the heterozygous (Gpil-1/Gpi1-2) 'Royal Violet' parent; lanes 2,3, and 18 are from (Gpil-1/Gpil-1) homozygotes; and lanes 9, 13, and 17 are from (Gpil -2/Gpil-2) homozygotes. All other lanes are from heterozygous progeny. Origin is at the top of the photograph. 


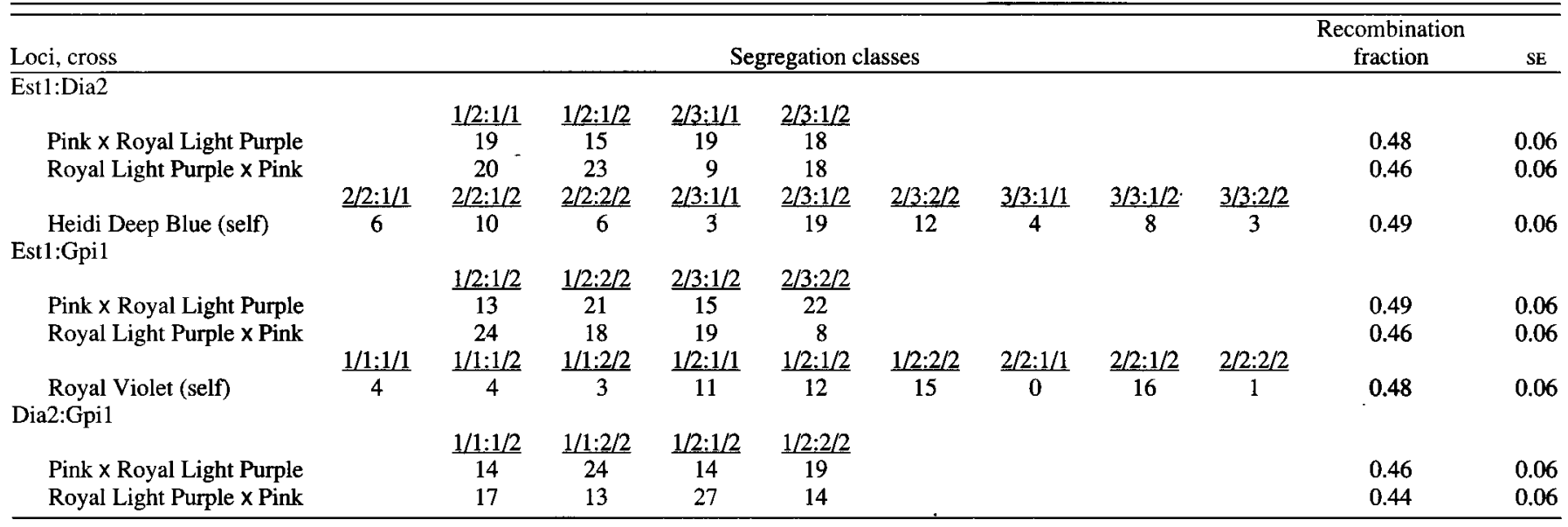

was supported by the observed segregation ratios for this isozyme (Table 2). Allelic designations of Dia2-1 for the faster band (Rm 1.00) and Dia2-2 for the slower band (Rm 0.73 ) are proposed. In plants, DIA may have a monomeric, dimeric, or tetrameric structure (Weeden and Wendel, 1989). For lisianthus, heterozygous plants produced a five-band pattern that reflected a tetrameric enzyme structure.

GPI. One distinct anodal region of activity was produced for GPI with three banding patterns, each with one or two faster shadow bands (Fig. 3). Although moderately distorted segregation ratios for GPI $\left(X^{2}=3.17, X^{2}=4.07\right)$ were found for reciprocal crosses between 'Royal Light Purple' and 'Pink' (Table 2), the observed segregation ratio for the self-pollination of 'Royal Violet' supported a model of one locus (Gpil) with two alleles $\left(X^{2}=0.33\right)$. Distorted segregation ratios could arise from one or more of several genetic, genomic, or chromosomal phenomena such as pre- or postzygotic selection or chromosomal translocation (Wendel and Parks, 1984).

Allelic designations of Gpil-1 (Rm 1.00) and Gpil-2 (Rm 0.93) are proposed. Heterozygotes produced a smear pattern, therefore, the expected dimeric enzyme structure (Weeden and Wendel, 1989) could not be confined.

Joint segregation data indicate that inde- pendent segregation occurs among the three proposed loci (Table 3). Therefore, the frost three simply inherited, unlinked biochemical markers in lisianthus have been identified. These marker loci will be useful for genetic studies, breeding, and germplasm characterization. Screening abroad range of germplasm for isozyme polymorphism may result in the development of additional genetic markers in lisianthus.

\section{Literature Cited}

Griesbach, R.J. and R.N. Bhat. 1990. Colchlcineinduced polyploidy in Eustoma grandiflorum. HortScience 25:1284-1286.

Griesbach, R.J. and P. Semeniuk. 1987. Use of somaclonal variation in the improvement of Eustoma grandiflorum. J. Hered. 78:114-116.

Halevy, A.H. and A.M. Kofranek. 1984. Evaluation of lisianthus as anew flower crop. HortScience 19:845-847.

Kobayashi, R.S., J.L. Brewbaker, and H. Kamemoto. 1987. Identification of Anthurium andraeanum cultivars by gel electrophoresis. J. Amer. Soc. Hort. Sci. 112:164-167.

Messeguer, R. and P. Ares. 1985. Electrophoretic identification of carnation cultivars. HortScience 20:372-373.

Mowrey, B. D., D.J. Werner, and D.H. Byrne. 1990. Inheritance of isocitrate dehydrogenase, malate dehydrogenase, and shikimate dehydrogenase in peach and peach $\mathrm{x}$ almond hybrids. J. Amer. Soc. Hort. Sci. 115:312-319.
Rob, M. and R. Lawson. 1984. The lure of lisianthus. Greenhouse Manager 2:103-121.

Rubino, D.B. 1991. Isozyme variation in cultivated Exacum affine and Eustoma grandiflorum germplasm. HortScience 26:775. (Abstr.)

Rubino, D.B. 1992. Trials rate lisianthus cultivars. Greenhouse Manager 10:86-88.

Stuber, C.W., J.F. Wendel, M.M. Goodman, and J.S.C. Smith. 1988. Techniques and scoring procedures for starch gel electrophoresis of enzymes from maize (Zea mays L.). North Carolina State Agr. Res. Serv. Tech. Bul. 286.

Suiter, K.A., J.F. Wendel, and J.S. Case. 1983. Linkage- 1: A Pascal computer program for the detection and analysis of genetic linkage. J. Hered. 74:203-204.

Sumanasinghe, V.A. 1986. Electrophoretic, cytogenetic, crossability, and morphological studies of exacum (Gentianaceae). PhD Diss., The Pennsylvania State Univ., University Park.

Weeden, N.F. and J.F. Wendel. 1989. Genetics of plant isozymes, p. 46-72. In: D.E. Soltis and P.S. Soltis (eds.). Isozymes in plant biology. Dioscorides Press, Portland, Ore.

Wendel, J.F. and C.R. Parks. 1982. Genetic control of isozyme variation in Camellia japonica L. J. Hered. 73:197-204.

Wendel, J.F. and C.R. Parks. 1984. Distorted segregation and linkage of alcohol dehydrogenase genes in Camellia japonica L. (Theaceae). Biochem. Genet. 22:739-748.

Wendel, J.F. and N.F. Weeden. 1989. Visualization and interpretation of plant isozymes, p. 5-45. In: D.E. Soltis and P.S. Soltis (eds.). Isozymes in plant biology. Dioscorides Press, Portland, Ore. 